5. Гравиразведка: справ. геофизика / под ред. Е.А. Мудрецовой, К.Е. Веселова. - 2-е изд. перераб. и доп. - М.: Недра. 1990. - 607 с.: ил.

6. Долгаль А.С. Декомпозиция решения обратной задачи гравиразведки рудного типа монтажным методом // Вестн. КРАУНЦ. Сер. Науки о Земле. - 2019. - № 1 (41). - C. 25-36. - DOI: 10.31431/18165524-2019-1-41-25-36.

7. Долгаль А.С., Костицын В.И., Новикова П.Н., Пугин А.В. Алгоритмы аппроксимации геопотенциальных полей истокообразными функциями // Геофизика. - 2016. - № 5. - С. 4-10.

8. Математический форум Math Help Planet [Электронный pecypc] - URL : http://mathhelpplanet.com/static.php?p=iteratsionnyi-metod-shultsa-nakhozhdeniya-obratnoi-matr itsy (Дата обращения 2.04.2020 г.)

9. Пугин А.В. Истокообразные аппроксимации геопотенциальных полей. От теории к практике // Геофизические исследования. - 2018. - Т.19, № 4. - С. 16-30. DOI:10.21455/gr2018.4-2.

10. Фаддеев Д.К. Об обусловленности матриц // Труды математического института АН СССР. - 1959. Т. 53. - С. 387-391.

11. Форсайт Д., Молер К. Численное решение систем линейных алгебраических уравнений: пер. с англ. М.: Мир, 1969. - 166 с.: ил.

\title{
ИЗУЧЕНИЕ СТРОЕНИЯ ЗОН ВЫКЛИНИВАНИЯ ПЛАСТОВ ВОДОЗАЩИТНОЙ ТОЛЩИ СОЛЯНЫХ РУДНИКОВ КОМПЛЕКСОМ ШАХТНОЙ И НАЗЕМНОЙ СЕЙСМОРАЗВЕДКИ
}

\author{
И.А. Санфиров \\ Горный институт УрО РАН, г. Пермь
}

\begin{abstract}
Аннотация: Латеральная изменчивость толщин водоупорных пластов на месторождения водорастворимых полезных ископаемых - обычное геологическое явление. В отдельных случаях оно может принимать и критические формы вплоть до полного выклинивания, например в пределах разного рода положительных структур. Картирование границ выклинивания данных пластов, определяющих возможность ведения горных работ, предлагается на основе результатов сейсморазведочных исследований, как с поверхности, так и во внутренних точках среды. В качестве информационного обеспечения формирования интерпретационных заключений в дополнение к волновым картинам в первую очередь рассматриваются различные динамические характеристики разноуровенных волновых полей: амплитуды и двумерные амплитудные спектры. Привлекаются также данные о распределении эффективных скоростей в пределах плоскости профиля.

Ключевые слова: сейсморазведка, двумерные спектры, зона выклинивания, скоростная характеристика, интерференция, Верхнекамское месторождение.
\end{abstract}

Для Верхнекамского месторождения известен ряд поднятий, осложненных куполами, в пределах которых выклиниваются продуктивные и вмещающие их отложения [1]. Очевидно, что при уменьшении толщин пластов, защищающих калийную залежь от воздействия водоносных горизонтов надсоляных отложений, ведение горных работ становится невозможно. В этой связи прогноз пространственных координат «нулевой» изопахиты соляных пластов, входящих в состав водозащитной толщи (В3Т), крайне важен для обеспечения безопасности ведения горных работ.

Задача определения границ зон выклинивания отдельных литологических комплексов хорошо известна из практики сейсморазведочных исследований по методике многократных перекрытий [2], при поисках и разведке месторождений углеводородов. Актуальность изучения подобных объектов связана с прогнозом неструктурных ловушек [3]. Очевидно, что прямое решение за счет повышения частотного диапазона регистрируемого волнового поля, объективно ограничено технологическими возможностями реализуемых систем наблюдений.

Целесообразность разработки специализированных методических приемов, связанных с усложнениями полевого процесса, также не всегда очевидна. Перспективы дета- 
лизации границ зон выклинивания при предельной разрешающей способности, соответствующей используемым полевым технологиям, связаны с привлечением в интерпретационный процесс параметров волнового поля, наиболее информативных в подобной ситуации.

Решения прямых задач $[4,5]$ с различным уровнем приближения к реальным условиям показывают, что для подобных объектов определяющим свойства волнового поля является соотношение переменной временной мощности выклинивающегося пласта и достигнутого частотного состава регистрируемого волнового поля. За счет изменения данного соотношения на участке отсутствия раздельных от кровли и подошвы пласта отражений можно выделить целый ряд особенностей волнового поля:

1) в значениях амплитуд окончательного временного разреза проявляются эффекты диструктивной и конструктивной интерференции (рис.);

2) распределение значений эффективных скоростей приобретает форму, соответствующую изучаемому объекту;

3) по мере уменьшения временного сдвига интерферируемых отражений преобладающие частоты в соответствии с теоремой запаздывания [6] смещаются в область повышенных значений.

Для анализа первого и второго из перечисленных критериев не требуется каких-либо дополнительных процедур цифровой обработки, кроме необходимых для получения качественного временного разреза. Данные о их поведении представлены в стандартном наборе результатов цифровой обработки: динамический временной разрез и скоростная характеристика [7].

Изучение закономерностей изменения спектров требует выполнения определенных условий [4]. Во-первых, необходимо на временном разрезе определить интервал, в котором находится изучаемый объект, т.е. на основании второго критерия привести первый в соответствие с априорной геологической информацией. Далее во временном окне, соответствующем данному интервала, но с размерами не менее двух периодов сейсмических колебаний, представленных на временном разрезе, выполняется расчет амплитудных спектров. Спектры визуализируются аналогично временному разрезу, где вместо трасс суммарной сейсмозаписи в координатах частот и профиля представляются их амплитудные спектры (рис.). Таким образом, процедура прогнозирования включает ряд простых операций:

1) определение на профиле участка с переменной толщиной пластов водозащитной толщи по особенностям волновой картины и с учетом геологической информации;

2) выбор временного интервала для формирования интерпретационного заключения, на основании результатов скоростного анализа и волновой картины, представленной на окончательном временном разрезе;

3) потрассный спектральный анализ в выбранном временном интервале;

4) линейная интерполяция в область высоких частот максимальных значений амплитудных спектров на участке интерференции отражений от кровли и подошвы «клина»;

5) контроль координат «точки пересечения» линии интерполяции максимумов спектров с осью частот по особенностям поведения амплитудной (динамический разрез) и кинематической (скоростная характеристика) составляющих волновой картины на участке интерференции отражений от кровли и подошвы «клина».

Применение подобной интерпретационной технологии позволяет принимать обоснованные решения о существовании либо отсутствии контролируемых пластов на пределе разрешающей способности анализируемого волнового поля в $1 / 4$ длины волн.

Основные отличия волновых полей наземной и шахтной сейсморазведки связаны с существенно различным частотным диапазоном результирующей сейсмической записи, представленной на временных разрезах. При выполнении наземных 
сейсморазведочных наблюдений с регистрацией продольного типа волн речь идет о преобладающей частоте в 60-80 гц, а для шахтных наблюдений - 300-600 гц. При скоростях распространения упругих волн продольного типа в $3200-3400 \mathrm{~m} / \mathrm{c}$ для наземных и в 3800-4000 м/с для шахтных сейсморазведочных наблюдений пределы разрешающей сейсморазведки составят 10-14 м и 1.6-3.3 м соответственно. Согласно этим критериям и определяются потенциальные возможности прогнозирования.

В случае комплексирования наземных и шахтных сейсморазведочных наблюдений [8] применение более информативных шахтных исследований ограничивается результатами наземных. При прогнозировании участков с критическими значениями мощности переходной пачки и покровной каменной соли в диапазоне менее $10 \mathrm{M}$ очевидно, что проведение горных работ там нецелесообразно. Следовательно, и проведение шахтных сейсморазведочных исследований становится нереальным. С другой стороны, при достаточно неравномерной плотности наземных сейсморазв едочных исследований в пределах действующих шахтных полей соляных рудников возможны ситуации с проходкой разведочных выработок на площадях с критическими изменениями мощности ВЗТ. В подобных ситуациях совместная интерпретация разноуровенных и разнонаправленных волновых полей безусловно повышает достоверность прогнозов контура «нулевых» изопахит водоупорных пластов надсоляной толщи.

В качестве практического примера реализации предложенной интерпретационной технологии рассмотрим результаты наземных и шахтных сейсморазведочных исследований на одном из участков Верхнекамского месторождения.

Результаты цифровой обработки и интерпретации шахтных сейсмоакустических данных представлены на рис. 1, а. Основные отражающие горизонты приурочены к кровлям пластов: В (ОГ Вк), Г (ОГ Гк), Д (ОГ Дк), Е (ОГ Ек), ПКС (ОГ ПКСк), к подошве покровной каменной соли - ОГ ПКСп. Отражающий горизонт ППк приурочен к интервалу кровли переходной пачки.

В пределах профильной линии в исследуемом интервале геологического разреза выделено три участка с осложнениями волнового поля: 1) 0-80 м, 2) 220300 м, 3) 440-520 м. Все выделенные участки отмечаются резкими перепадами распределения эффективных скоростей на скоростной характеристике (рис. 1, б) на общем фоне смещения пониженных значений вверх по разрезу к началу профиля.

В структуре волновой картины все выделенные участки приурочены к зонам «ступенчатого» уменьшения временной мощности пластов каменной соли в надпродуктивной толще ОГ ПП - ОГ ПКСп и сопровождаются латеральной изменчивостью интенсивности сейсмической записи на линамическом временном разрезе (рис. 1, б). Налицо все признаки наличия пласта переменной мощности, конфигурация которого наиболее наглядна после процедуры миграции (рис. 2, а).

В пределах выделенных участков на двумерном амплитудном спектре временного разреза (рис. 2, б) отмечаются зоны смещения преобладающих частот в область более высоких значений. Максимальное уменьшение мощности очевидно в пределах первого участка и после 50 м к началу профиля находится за пределами разрешающей способности анализируемых данных, т.е. меньше 2 м (1/4 длины волны). Аналогичный анализ проведен и по результатам наземных сейсморазведочных наблюдений (рис. 3). Учитывая разрешающую способность данных материалов, можно предположить, что начиная с 3550 м мощность соляных пластов в надпродуктивных отложениях меньше 10 м (1/4 длины волны). 
Совместный анализ динамических (частота) и кинематических (время) по наземным и шахтным профилям позволяет локализовать границу пониженных толщин соляных пластов в надпродуктивной толще в среднем менее 6 м, что может являться основанием для корректировок границ аномалий, в обязательном порядке учитываемых при разработке калийной залежи.
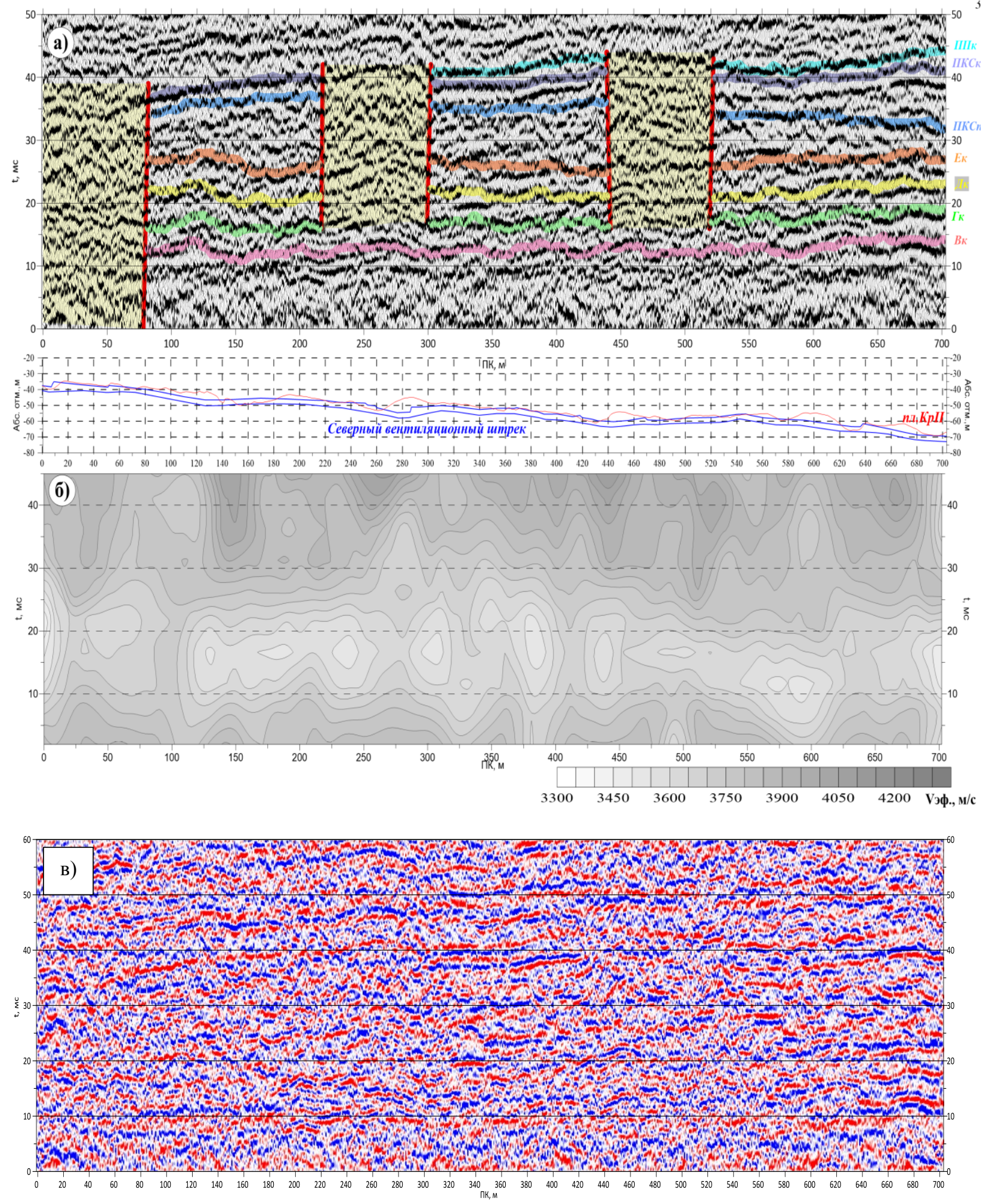

Рис. 1. Временной разрез МОГТ (а), скоростная характеристика (б), динамический временной разрез (в) 

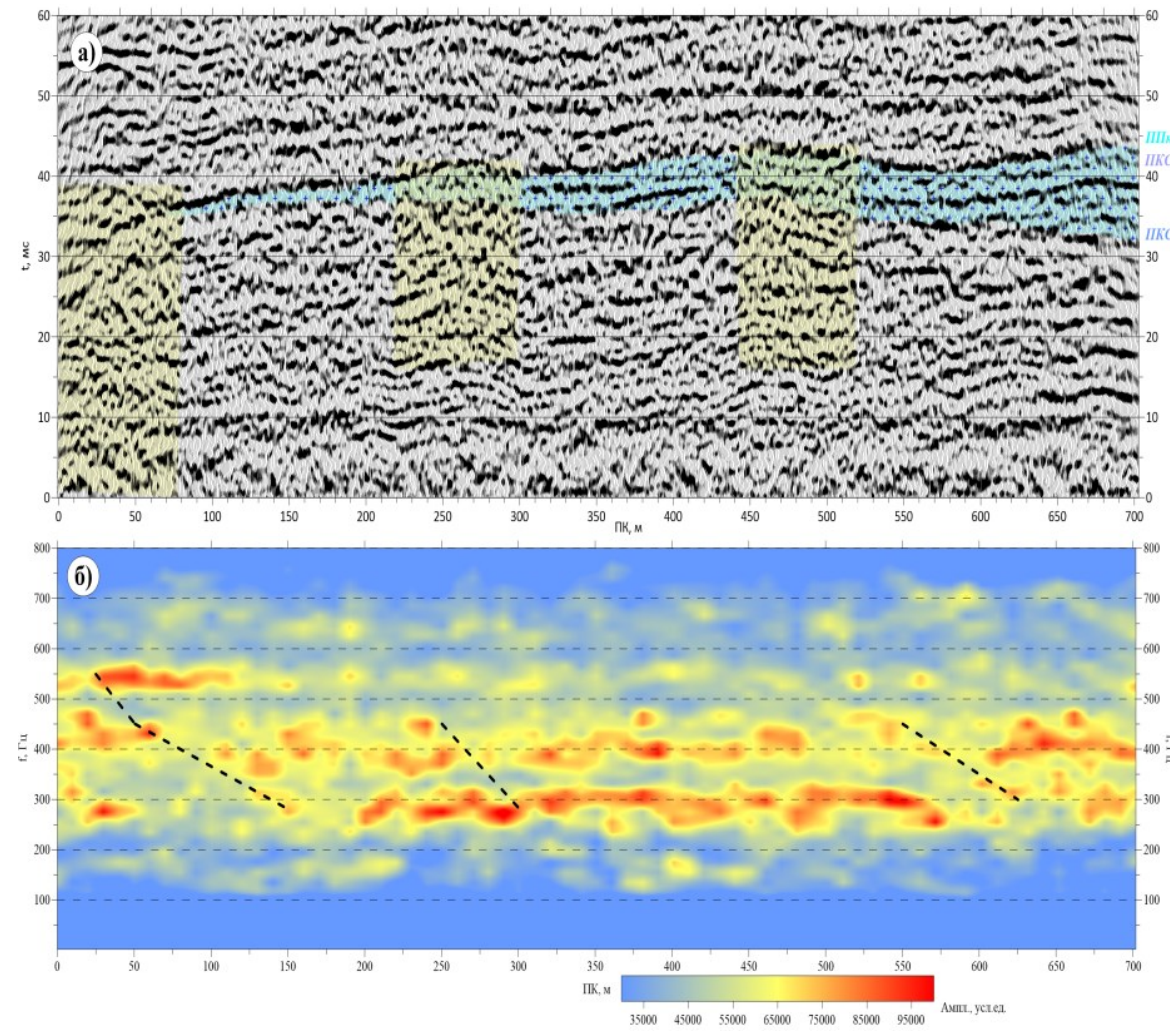

Рис. 2. Миграция временного разреза (а) и двумерный амплитудный спектр (б), рассчитанный в интервале 30-50 мсек.
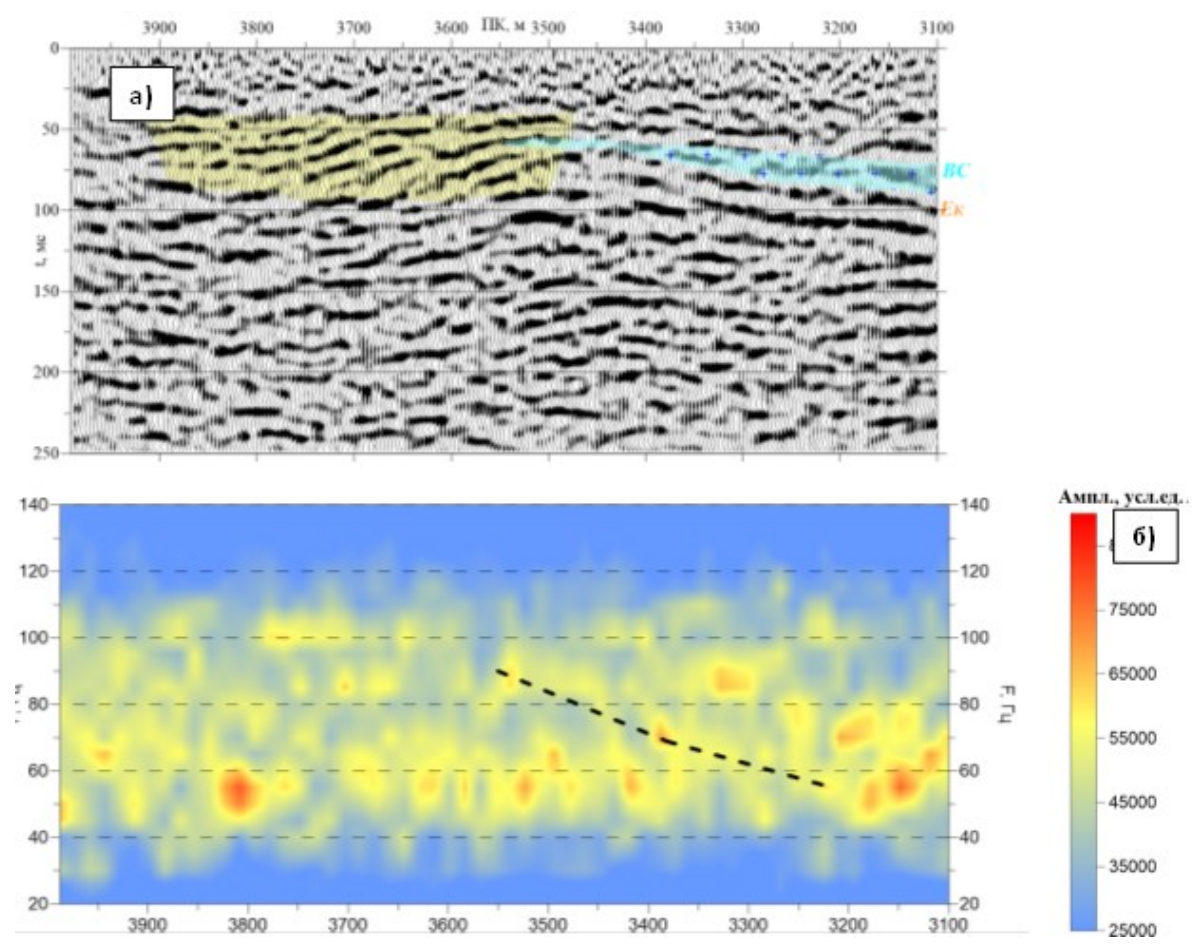

Рис. 3. Временной разрез (а) по данным наземной сейсморазведки и его двумерный спектр (б) в интервале 50-100 мс.

Исследование выполнено при финансовой поддержке Программы ФНИ, проект № 0422-2019-0146-С-02 (регистрационный номер темы НИОКТР: АAАA-А18118040690028-5). 


\title{
БИБЛИОГРАФИЧЕСКИЙ СПИСОК
}

1. Петротектонические основы безопасной эксплуатации Верхнекамского месторождения калийномагниевых солей / под ред. Н.М. Джиноридзе. - СПб; Соликамск, 2000. - 400 с

2. Мешбей В.И. Методика многократных перекрытий в сейсморазведке. -М.: Недра, 1985. - 264 с.: ил.

3. Нейдель И.С., Поджиаглиолми Э. Геофизическое обоснование и методика сейсмостратиграфического моделирования и интерпретации // Сейсмическая стратиграфия. Использование при поисках и разведке нефти и газа / под ред.Ч. Пейтона. - М., 1982. - Ч. 2. - С. 645-692.

4. Санфиров И.А., Ильичев Ю.В. Результаты изучения зоны выклинивания продуктивных отложений способами динамического анализа // Разведочная геофизика: отечеств. производств. опыт: экспрессинформ. / ВИЭМС. - М., 1988. - вып. 6. - С. 14-20.

5. Shoenberger M., Levin F.K. Reflected and transmitted filter functions for simple subsurface geometries // Geophysics. - 1976. - V.41, № 6. - P. 1305-1317. DOI: 10.1190/1.1440681.

6. Бат М. Спектральный анализ в геофизике: пер. с англ. - М.: Недра, 1980. - 535 с.: ил.

7. Санфиров И.А.,. Бабкин А.И,. Ярославцев А.Г, Прийма Г.Ю,.Фатькин К.Б. Сейсморазведочные исследования условий разработки калийной залежи // Геофизика. - 2011. - № 5. - С. 53-58.

8. Барях А.А., Санфиров И.А., Федосеев А.К., Бабкин А.И, Цаюков А.А Сейсмо-геомеханический прогноз состояния водозащитной толщи на калийных рудниках // Физико-технические проблемы разработки полезных ископаемых. - 2017. - № 6. - C. 10-22. DOI: 10.15372/FTPRPI20170602.

\section{РАЗРАБОТКА МЕТОДИКИ МОНИТОРИНГОВЫХ ГРАВИМЕТРИЧЕСКИХ ИССЛЕДОВАНИЙ ДЛЯ ИЗУЧЕНИЯ КАРСТОВЫХ ПРОЦЕССОВ}

\author{
А.А. Симанов \\ Горный институт УрО РАН, г. Пермь
}

\begin{abstract}
Аннотация: Карст является одним из наиболее сложных и трудно прогнозируемых геологических процессов, представляющих опасность для жизнедеятельности урбанизированных территорий. Процесс сопровождается образованием специфических форм рельефа, подземных пространств (каверны, полости, системы полостей) и обусловливает развитие деформационных явлений различного характера (обрушения, провалы, оседания).

Вместо констатации фактов провалов и обрушений, что практикуется в настоящее время при изучении карстовых явлений, предлагается применять методику мониторинговых гравиметрических исследований, которая позволит получать сведения о геологическом строении массива, об участках с интенсивным развитием карстово-суффозионных процессов, о наличии полостей на начальном этапе их развития. Это позволит сориентировать инженерные работы по обеспечению сохранности и безопасной жизнедеятельности.

Представлены результаты гравиметрических работ, проводимых с целью изучения последствий разработки Верхнекамского калийного месторождения. Показано, что современные методы обработки и интерпретации высокоточных мониторинговых исследований существенно повышают возможности прогнозирования негативных инженерно-геологических явлений. Приведены примеры гравиметрических исследований на аварийных участках рудников.
\end{abstract}

Ключевые слова: гравиразведка, мониторинг, аномалия гравитационного поля, динамическая гравитационная аномалия, обратные задачи геофизики.

Проблема изучения горного массива, расположенного над естественными или техногенными полостями в геологическом пространстве, существует уже давно. К естественным полостям относятся пещеры доступные для проникновения. К техногенным горные выработки шахтного производства, а также подземные коммуникационные сети на урбанизированных территориях. От сохранности массива горных пород над этими полостями часто зависит безопасность жизнедеятельности населения, сохранность самого рудника или природного объекта. Изучение территории с поверхности посредством геофизических наблюдений даёт хорошие результаты как с точки зрения выявления ослабленных или потенциально опасных зон (при однократно проведенной 